\title{
Analysis of trends in emergency department attendances, hospital admissions and medical staffing in a Hong Kong university hospital: 5-year study
}

\author{
Abraham K. C. Wai • C. M. Chor • Allen T. C. Lee • \\ Yuwares Sittambunka • Colin A. Graham • \\ Timothy H. Rainer
}

Received: 19 May 2008 / Accepted: 11 February 2009 / Published online: 8 April 2009

(C) Springer-Verlag London Ltd 2009

\begin{abstract}
Background The workload of emergency departments (ED) continually changes in response to presentations, overcrowding and availability of expertise and investigations. Aims To investigate changes in ED presentations and care processes, and the relationship of patient demand and ED staff resources to waiting times and processing times. Methods Retrospective analysis of prospectively collected administrative data from January 1999 to April 2005 in an emergency department in a university teaching hospital in Hong Kong. All patients attending the emergency department during the study period were included. Monthly attendance data were retrieved and analysed to determine both qualitative and quantitative changes in the patterns of presentation to the ED using prospectively gathered data. Results Total ED attendances decreased by $25 \%$ during the study with little seasonal variation. The admission rate and the use of ambulances increased steadily and significantly. Medical patients are increasing proportionately, but trauma patients are decreased in number.

Conclusion There have been major changes in the patterns of ED attendances and ED waiting times over the study period in this teaching hospital ED. Decreasing overall ED
\end{abstract}

The views expressed in this paper are those of the authors, and not those of the editors, editorial board or publisher.

A. K. C. Wai · C. M. Chor · A. T. C. Lee • Y. Sittambunka •

C. A. Graham $(\triangle) \cdot$ T. H. Rainer

Accident and Emergency Medicine Academic Unit,

Chinese University of Hong Kong, Trauma \& Emergency Centre,

Prince of Wales Hospital, Shatin,

New Territories, Hong Kong SAR

e-mail: cagraham@cuhk.edu.hk numbers are offset by an increasingly elderly population and a more complex case mix. Reducing clinical staff numbers appears to reduce the ED's capacity to provide timely assessments and care and to function as hospital gatekeepers. Restoring staff numbers to previous levels may improve the quality and timeliness of ED services. It is necessary to refine measures of ED complexity and workload to determine appropriate staffing levels in the future.

Keywords Hong Kong · Emergency departments . Case mix $\cdot$ Attendances $\cdot$ Admissions $\cdot$ Demand $\cdot$ Resources

\section{Introduction}

Over the last 50 years, demands on emergency departments (EDs) have dramatically changed both quantitatively and qualitatively. In the early years of emergency care, EDs received a limited number of patients, most of whom had experienced some form of injury. With demographic changes in society, increasing life expectancy and greater personal and clinical expectations, EDs now deal with a greater proportion of patients with medical illnesses rather than traumatic injury, and attendance rates have soared [1-13].

Overcrowding in EDs is well recognised to contribute to poor outcomes, increased mortality, and poor staff morale. Access block is commonly encountered in the ED, and is a function of hospital-wide issues with poor discharge planning and lack of beds being common causes. Increased expectations from patients, emergency physicians, and other clinicians has led to increasing demands on ED services, and higher expectations of definitive diagnosis has 
led to more testing and radiological investigations being performed in the ED setting.

Point of care testing has extended this further and means that some patients who previously would have been admitted to hospital to exclude a particular condition are now treated solely in the ED. These 'rule-out' strategies are clearly favoured by patients as they do not demand hospital admission, but they increase the demands on the ED considerably. Consequently, EDs have a major role as gatekeepers of the hospital, ensuring that patients are appropriately admitted or discharged, and that hospital beds are well utilised.

Three major factors have affected health care in Hong Kong in the new millennium - the Harvard report [14], the adverse global economic climate [15-18], and the outbreak of Severe Acute Respiratory Syndrome (SARS) [19-21]. The Harvard report and economic pressures led to the introduction of a HK\$ 100 ( US\$13) charge for patients attending EDs, effective from November 2002. The charge was introduced partly in an attempt to reduce the number of patients attending EDs who probably do not have emergency illnesses or injury, and partly to raise revenue to support the Hospital Authority's financial deficit. The introduction of charges was rapidly followed by the SARS outbreak in February 2003.

The objective of this study is to investigate changes in emergency department (ED) presentations, hospital admissions, and ED staffing over 5 years, and to investigate the relationship between patient demand, ED staff resources, and waiting times and processing times, in a mixed adult/ paediatric emergency department in a Hong Kong university teaching hospital.

\section{Methods}

This observational study was a retrospective analysis of data collected prospectively for an ED administrative database. The study was undertaken in Prince of Wales Hospital (PWH), a university teaching hospital and tertiary referral facility with 1,400 beds. It opened in 1984 and is the primary teaching hospital of the Chinese University of Hong Kong. The ED at PWH is situated near the centre of a highly developed new town and provides a 24 -h, specialistled emergency medicine service for both adults and children, serving a population of 630,000 people in Shatin district. It serves as the trauma centre for the New Territories of Hong Kong, covering the Shatin, Tai Po, and North District areas with a total population of about 1.31 million people [22-24].

All clinical services are available on-site. A second computed tomography (CT) scanner was installed in the ED in December 2004, in addition to the main hospital CT scanner, which the ED had previously been able to access for urgent scans. ED point-of-care testing includes troponin $\mathrm{T}$, glucose, and haemoglobin testing, along with arterial blood gas analysis. Analyses from the main chemical pathology and haematology laboratories are usually available within $2 \mathrm{~h}, 24 \mathrm{~h}$ a day, for ED samples. A 6-h troponin T- and ECG-based chest pain protocol is used to reduce hospital admissions due to low risk chest pain.

Hong Kong does have private general practitioners, some of whom have formal training in family medicine, but they tend to be used mainly by those with health-care insurance or those who can afford their fees. Patients who cannot personally afford the costs, or who lack insurance, typically come to the ED for many of their health-care needs. The emergency ambulance service is accessed by dialing '999' from any telephone in Hong Kong, and it is free to all users.

In the study, monthly data for PWH ED between January 1999 and April 2005 were retrieved and analysed in order to determine quantitative changes in the $\mathrm{ED}$ caseload using the Accident and Emergency Information System (AEIS), a Hong Kong-wide ED data capture and management system.

The following data were retrieved: monthly attendance, numbers of trauma and non-trauma cases, number of ambulance attendances and admissions, rate of unplanned re-attendance within $48 \mathrm{~h}$, number of admissions, number of cases in triage categories 1 to 5 , average waiting time, average processing time, and the number of emergency medical and nursing staff.

Every patient who attends the ED goes through a triage process and is assigned one of five categories. The definitions of the five categories of severity are shown in Table 1. A typical ED in Hong Kong is divided into resuscitation rooms that manage category 1 and 2 cases, cubicles for trolley patients, and ambulatory areas where category 3-5 patients are managed.

In PWH ED, patients in categories 1 and 2 are seen immediately. There is a specific stream for category 3 patients between $0800 \mathrm{~h}$ and $2359 \mathrm{~h}$ daily, and category 4 trolley patients are also seen in a specific stream between $0800 \mathrm{~h}$ and $2200 \mathrm{~h}$ daily. Outside of these times, and for all category 4 and 5 cases who are ambulatory, there is no streaming, and patients are seen in the order in which they arrive.

Medical and nursing staffing was determined by reference to ED staffing records. Changes in overall staffing were determined by senior hospital managers outside of the ED.

Statistical analysis

Data were exported to Microsoft Excel (Microsoft Corporation, Redmond, WA) and StatView software (SAS Institute Inc, Cary, NC), which were used to generate 
Table 1 Triage system in Hong Kong

\begin{tabular}{|c|c|c|}
\hline Category & Patient's condition & Target response time and staff actions \\
\hline 1. Critical & $\begin{array}{l}\text { Suffers from a life-threatening condition(s) caused by a } \\
\text { major event } \\
\cdot \text { With unstable vital signs requiring immediate } \\
\text { resuscitation }\end{array}$ & $\begin{array}{l}\cdot \text { Immediate for all cases } \\
\cdot \text { Direct patient to resuscitation room } \\
\cdot \text { Attend patient immediately by a team comprising medical } \\
\text { and nursing staff }\end{array}$ \\
\hline 2. Emergency & $\begin{array}{l}\text { Suffers from a potentially life-threatening condition } \\
\text { Borderline vital signs but with potential risk of rapid } \\
\text { deterioration } \\
\text { - Requires emergency treatment and immediate } \\
\text { continuous close monitoring }\end{array}$ & $\begin{array}{l}\cdot<15 \text { min for } 95 \% \text { of cases } \\
\cdot \text { Direct patient to resuscitation room / treatment cubicle } \\
\cdot \text { Require medical attention and immediate continuous close } \\
\text { monitoring within } 15 \mathrm{~min}\end{array}$ \\
\hline 3. Urgent & $\begin{array}{l}\text { Suffers from a major condition with potential risk of } \\
\text { deterioration } \\
\text { - Stable vital signs }\end{array}$ & $\begin{array}{l}\cdot<30 \min \text { for } 90 \% \text { of cases } \\
\cdot \text { Direct patient to cubicle }\end{array}$ \\
\hline 4. Semi-urgent & $\begin{array}{l}\text { - Suffers from acute but stable condition(s) } \\
\text { - Stable vital signs } \\
\cdot \text { Can afford to wait some time without serious } \\
\text { complications }\end{array}$ & - Direct patient to cubicle/walk-in clinic \\
\hline 5. Non-urgent & $\begin{array}{l}\text { Suffers from minor and stable condition(s) (including } \\
\text { acute and non-acute conditions) } \\
\text { - Can afford to wait without deterioration } \\
\text { - Stable vital signs }\end{array}$ & $\begin{array}{l}\text { Direct patient to walk-in clinic } \\
\text { Remarks } \\
\text { - Conditions can be treated in primary health-care facilities } \\
\text { Should be based on clinical judgement only. Economic, } \\
\text { social factors and availability of facilities should not be } \\
\text { taken into consideration }\end{array}$ \\
\hline
\end{tabular}

graphical results. Categorical data were analysed using the chi-square test. Correlations between staffing levels and process and waiting times (average summary measures for each 12-month period) were performed using SPSS v13.0 (SPSS Inc, Chicago, IL). Statistical significance was set at $\mathrm{p}<0.05$.

\section{Results}

\section{Attendance}

Between January 1999 and April 2005, there were $1,115,592$ new patient visits to the ED at PWH. The overall monthly attendance and breakdown by triage category are shown in Fig. 1. Over the study period, there was a $29.5 \%$ reduction in overall mean monthly patient attendance from 17,371 in January 1999 to 12,254 in April 2005. Between 1999 and 2002 there were some winter peaks in category 3 cases, but otherwise there were no major seasonal variations.

An obvious and dramatic dip was seen early in 2003, which reflected patient behaviour during the global SARS outbreak. This decrease in attendance did recover, but not to pre-SARS levels. This reduction also followed the introduction of hospital charges in November 2002.
Figure 1 also shows triage category trends. Category 1 (critical) remained unchanged, but there was a small absolute increase in category 2 patients. Categories 3 and 4 also reduced in absolute numbers, while category 5 patients showed an increasing trend.

Hospital admission

There was a gradual increase in the overall admission rate from $17 \%$ in 1999 to $27 \%$ in 2005 . An increasing number of these admitted cases were brought to hospital by ambulance. The number of patients who were brought to the ED by ambulance increased markedly in both absolute and relative terms; in 1999 , there were only $2,129(12.8 \%)$ cases per month, and the figure almost reached 3,000 (21.5\%) monthly in 2004 .

More than half of all admitted patients were admitted to medical specialties, such as general medicine and paediatrics. Decreases in patient attendance were evident for general surgery, orthopaedics, paediatrics, and gynaecology. General medicine admissions increased, but obstetric admissions were steady.

There was also a reduction in trauma patients in both absolute and relative terms (Fig. 2). In 1999, there were 35,148 patient visits, accounting for $19 \%$ of total attendances at that time. In 2005, trauma attendances had decreased to 25,923 (16.4\%). However, the reduction in 


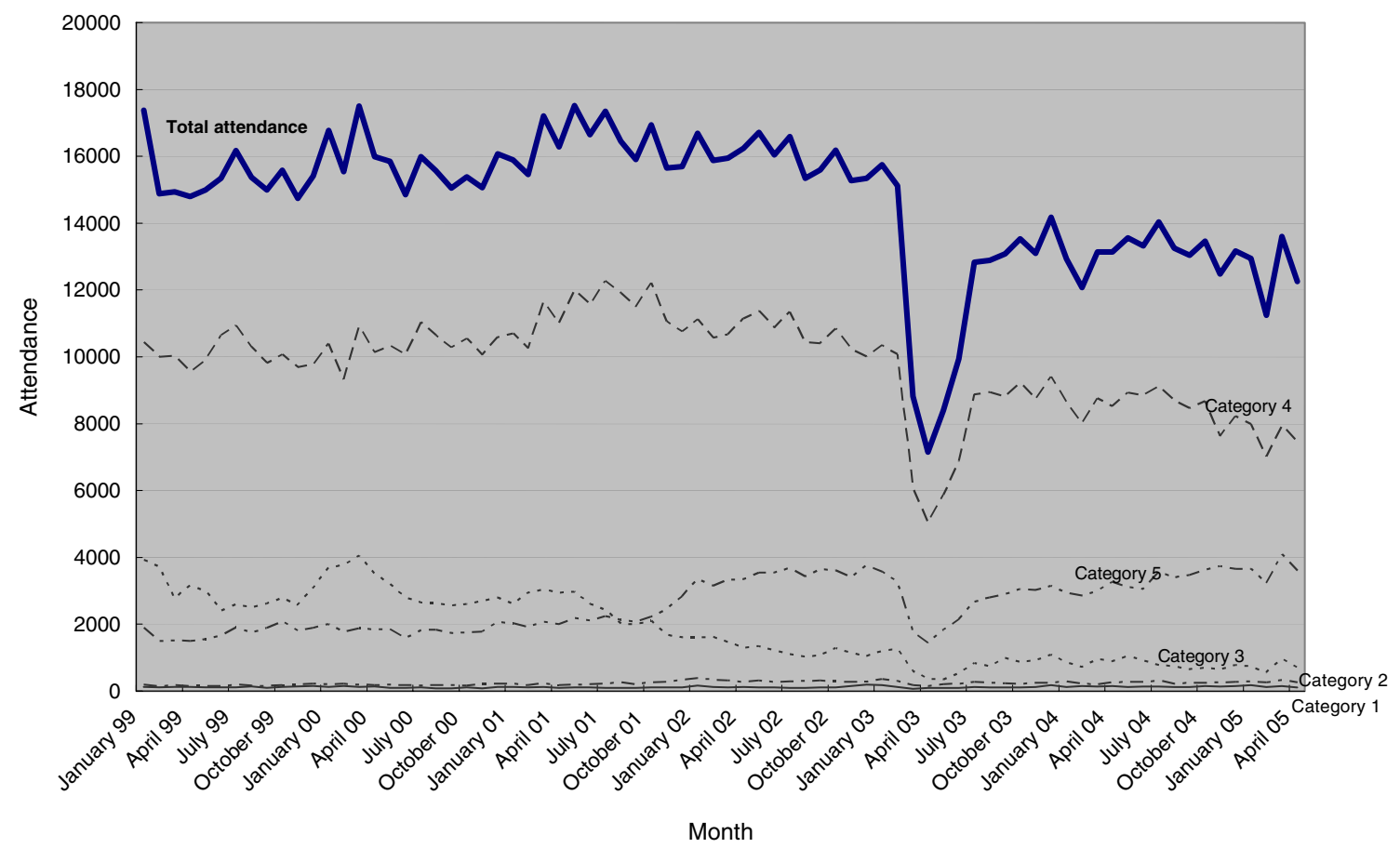

Fig. 1 Attendance in total and in different categories

non-trauma cases was even more pronounced than that seen in trauma (Fig. 2).

Figure 3 shows the effects of hospital clustering on the service. There were three acute hospitals in the New Territories East cluster; PWH, North District Hospital, and Alice Ho Nethersole Hospital. Prior to 2003, each hospital in the cluster only admitted its own cases, but in 2003, due to the SARS crisis and the subsequent pressures on the hospital system, the decision was made to utilise all beds in the cluster for patients needing emergency admission.

There was a gradual increase in waiting times, which is defined here as the time between ED registration and first assessment by an ED doctor (Fig. 4). The overall waiting time closely correlated with the waiting times for category 4 and 5 patients. Unplanned reattendance reduced gradually. In $1999,6,490$ patients (3.5\% of total attendance)
Fig. 2 Number of trauma and non-trauma attendance and their trend lines

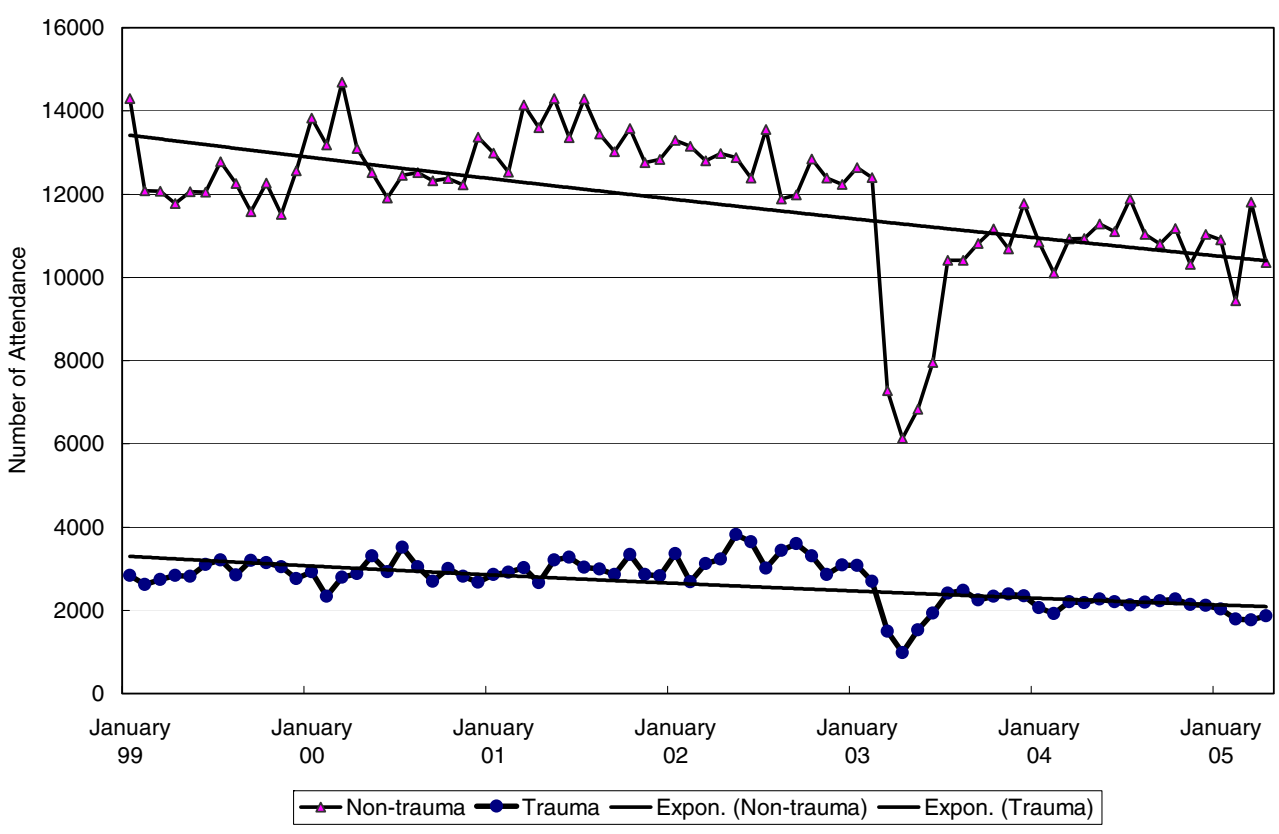


Fig. 3 Number of admissions to PWH and other cluster hospitals by month

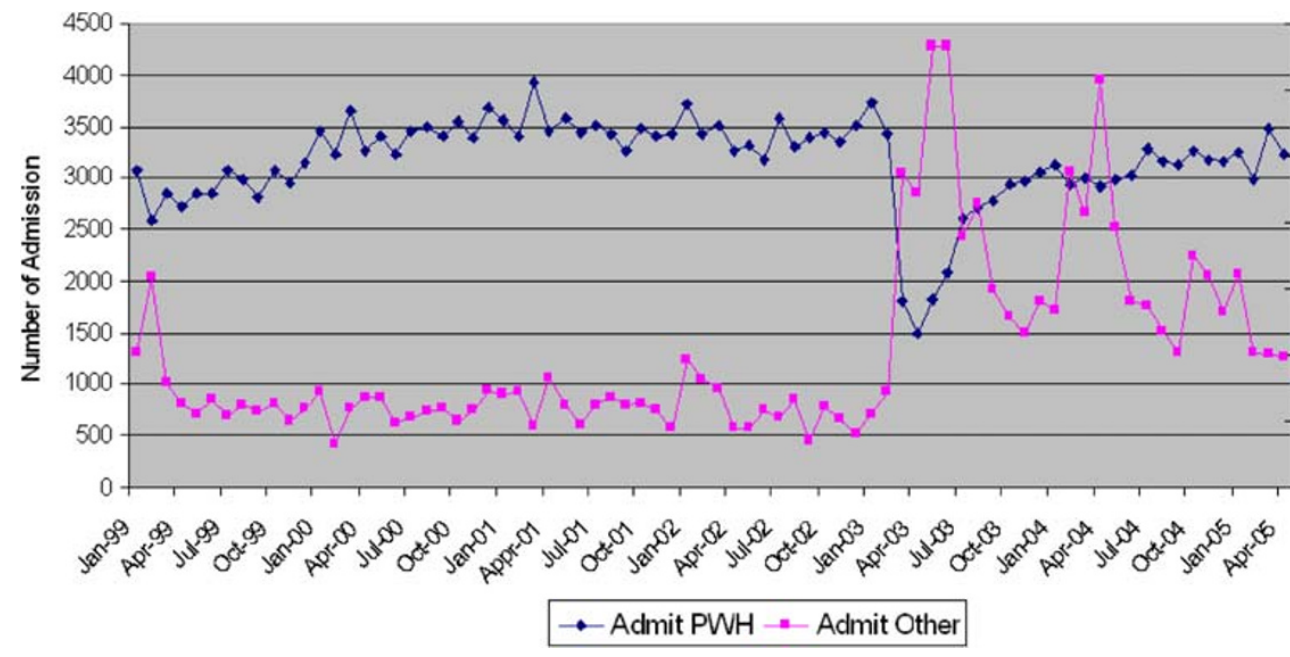

reattended the ED within $48 \mathrm{~h}$ of discharge. The figure decreased to $4,196(2.7 \%)$ in 2004.

\section{ED staffing}

Actual ED manpower over the study period also changed significantly (Table 2). Both medical and nursing staff numbers decreased since 2001. Medical numbers decreased nearly $25 \%$ from 38 to 30 , whilst nursing numbers decreased over $20 \%$ from 67 to 54 .

A positive correlation was observed between average waiting time and average process time $(\mathrm{R}=0.613,95 \% \mathrm{CI}$ 0.450 to $0737 ; p<0.0001)$. Negative correlations was ideally between the number of medical staff and the average waiting time $(\mathrm{R}=-0.539,95 \% \mathrm{CI}-0.682$ to $-0.357 ; \mathrm{p}<$ 0.0001 ), and the number of medical staff and the average process time $(\mathrm{R}=-0.704,95 \% \mathrm{CI}-0.802$ to $-0.568 ; \mathrm{p}<$ 0.0001).

Further negative correlations were identified between the number of nursing staff and the average waiting time $(\mathrm{R}=-0.349,95 \% \mathrm{CI}-0.533$ to $-0.135 ; \mathrm{p}=0.0018)$ and the number of nursing staff and the average process time $(\mathrm{R}=-0.542,95 \% \mathrm{CI}-0.684$ to $-0.361 ; \mathrm{p}<0.0001)$.

\section{Discussion}

This study shows that during the first 5 years of the 21st century, new patient attendances at PWH ED have decreased substantially. This reduction is not only in trauma, but also in non-trauma patients, and is most evident in category 3 and 4 triage cases. One distinct but transitory
Fig. 4 Waiting time from ED registration to first assessment by an ED doctor for different categories

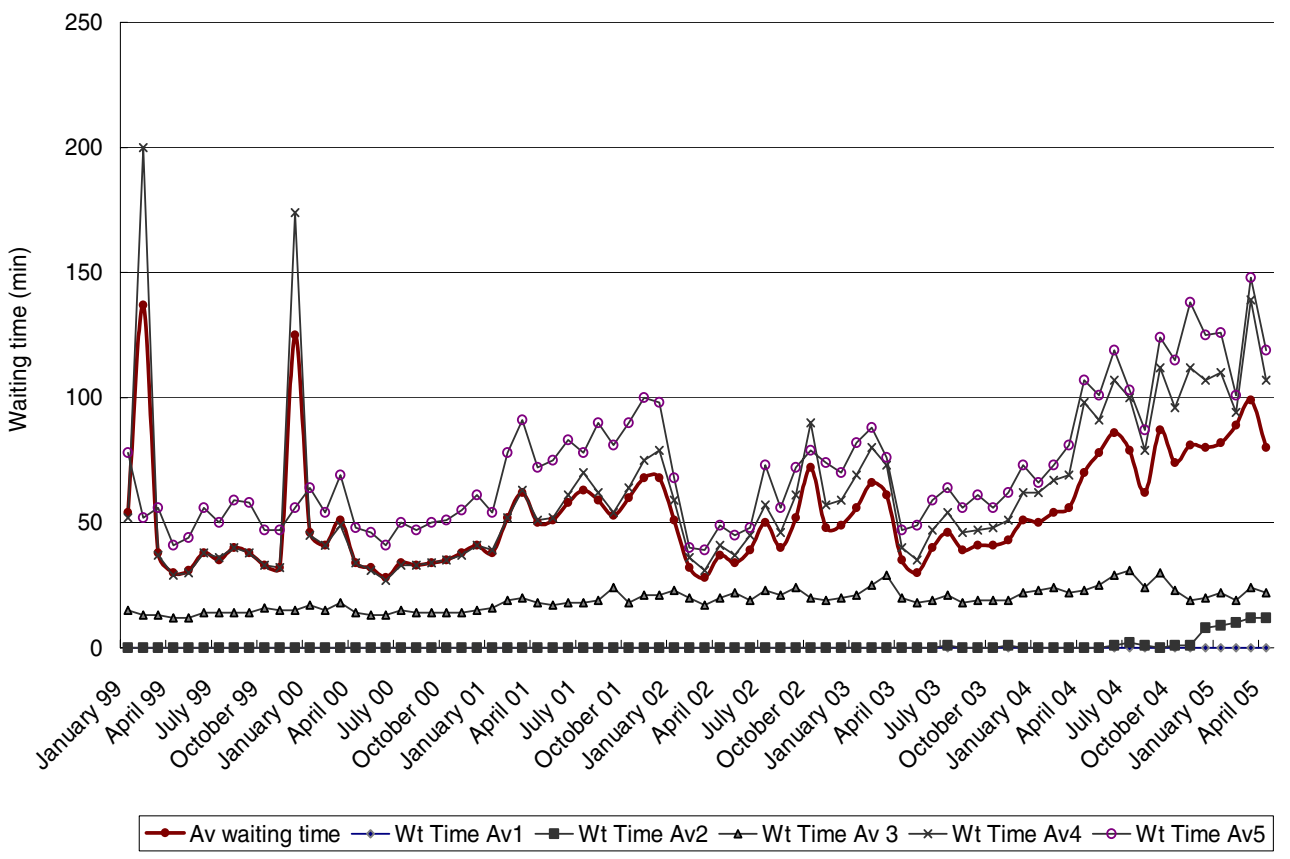


Table 2 ED staffing

\begin{tabular}{llll}
\hline Date & \multicolumn{2}{l}{ Number } & \\
\cline { 2 - 4 } & Nursing staff & $\begin{array}{l}\text { Senior medical } \\
\text { staff }\end{array}$ & Resident staff \\
\hline $31 / 12 / 00$ & 60 & 8 & 28 \\
$1 / 4 / 01$ & 67 & 7 & 29 \\
$31 / 12 / 01$ & 67 & 7 & 29 \\
$31 / 12 / 02$ & 66 & 6 & 32 \\
$1 / 7 / 03$ & 61 & 6 & 32 \\
$31 / 12 / 03$ & 61 & 5 & 27 \\
$31 / 12 / 04$ & 54 & 5 & 26 \\
$1 / 4 / 05$ & 54 & 5 & 25 \\
\hline
\end{tabular}

dip in attendance occurred early in 2003 because of the global SARS outbreak. The decrease in attendance is predominantly reflected in surgical specialties.

Despite the overall reduction in new patient attendances, there has been an increase in ambulance patients in the ED and a marked increase in the medical admission rate. The decrease in overall attendance rates has been accompanied by an overall decrease in staff numbers reflecting the hospital's policy of resourcing the ED according to the number of attendances rather than case mix and work load. Increases in waiting times have accompanied the $25 \%$ decrease in medical and nursing staff.

A sudden but transient decrease in total attendance followed the introduction of ED charges and the SARS outbreak. The failure of ED patient attendances to return to pre-SARS levels may be a result of changing public perceptions of the safety of hospitals, a realisation for some that the ED is intended for genuine emergencies rather than primary health-care needs, or a result of increasing ED charges.

Hong Kong began charging emergency room fees at public hospitals on 29 November 2002, ending a century-old tradition of free emergency treatment, with the immediate aim of reducing abuse of the emergency care system and as a step in the reform of health-care financing. Patients are now charged for ED services on arrival at the ED, but critically ill patients and patients who are unable to pay at the time of presentation are billed when they register. Payment is expected within 30 days.

However, those covered by the government-funded Comprehensive Social Security Assistance (CSSA) system do not pay any fee and may account for as many as 30\% of ED attendees. Current charges are still well below those charged by private general practitioners and do not reflect the true cost of providing emergency medical care. Thus, it is difficult to say whether the decrease in attendance is a result of SARS or of the introduction of fees.

The Hospital Authority (HA) revealed that the total ED attendance across Hong Kong climbed to its maximum in
$2001,75 \%$ of whom were classified as category 4 ('semiurgent') or category 5 ('non-urgent') cases. Following the implementation of the user-fee policy, there was $10 \%$ drop in ED attendance in the first year and a further $25 \%$ drop in the second year [25-26]. Reducing unnecessary ED attendances has been a health-care goal for some years. The unnecessary use of ED resources by patients with primary health-care problems [27] distracts medical and nursing staff from managing genuine emergencies.

Changes in triage categories may reflect changes in the presentations of patients, or they may reflect changes in triage assignment. Although clear triage protocols are in place, and local audit suggests that nurses follow these protocols closely, nevertheless there are still grey areas where patients may be upgraded or downgraded according to an individual nurse's judgement. The slight increase in the use of category 5 may not reflect increasing attendance of minor cases, but rather re-categorisation of some patients in light of increasing and changing demands.

The elderly population ( $\geq 65$ years) grew rapidly in our study period, with an annual growth rate of $12 \%$, compared with a 3\% annual growth rate for the general population. Since the introduction in 2003 of a Community Geriatric Service with old age home medical support, there has been a $30 \%$ reduction in the transfer of institutionalised patients to EDs [26]. The increase in both category 3 patients and ambulance cases may reflect the increasingly ageing population. These patients have more complex conditions due to more comorbidities which in turn may account for the increase in admission rates.

The decrease in admission to paediatric and surgical specialties may be partly explained by the decreasing birth rate, resulting in the reduction in the paediatric population in Hong Kong. Paediatricians are becoming more communitybased, and strong community paediatric support facilitates early discharge of young patients. It is also possible that surgical patients are using more private medical care to access earlier treatment. The reduction in trauma cases is well recognised throughout the developed world [28], due to reductions in road traffic accidents and elderly falls, and these factors may have contributed to the observed reduction in admissions.

Lee and colleagues [29-30] suggest that there are high levels of inappropriate ED utilisation, particularly in the evening and early morning. They suggest that factors associated with non-urgent use of the ED include higher socio-economic group, younger age, perceptions that their conditions are 'emergencies', and better quality of care at the ED. The ED is a convenient place for the general public to seek a medical opinion. Increasing ED attendance has been previously explained as a consequence of free service and treatment. Law and Yip [31] postulated three nonfinancial factors that affect ED attendances, including the 24-h coverage of EDs, higher quality of medical care in the 
ED than in local clinics, and inadequate health conditions. Reductions in medical and nursing staff may seem appropriate given the reduction in overall patient attendance, but increasing waiting and process times suggest that despite the decrease in numbers, workload has increased with a progressively complex, ageing population.

The strong correlations between increased process time and increased waiting times may not be surprising, but there was an even stronger correlation between the reduction in medical staff numbers and the increase in process time. This suggests that reductions in staff adversely impact waiting and process times for all patients despite the decrease in overall patient numbers, which lends support to increasing staff numbers back to their original levels at least.

\section{Conclusion}

There have been major changes in the patterns of ED attendances and ED waiting times over the study period in PWH. Decreasing overall ED numbers are offset by an increasingly aged population and a more complex case mix that demands more detailed assessment and seem to prolong ED waiting times. Reducing medical and nursing staff appears to reduce the capacity of EDs to provide timely assessments and care and to function as gatekeepers of the hospital. Returning staff numbers to previous levels may improve the quality and timeliness of ED services. It will be important to refine ED measures of complexity and workload to determine appropriate staffing levels in the future.

Funding None.

\section{Conflicts of interest None.}

\section{References}

1. Margolis SA, Reed RL (2002) Changing use of the emergency department by the elderly in the United Arab Emirates, 1989 and 1999. East Mediterr Health J 8(2-3):409-415

2. Selasawati HG, Naing L, Wan Aasim WA et al (2004) Inappropriate utilization of emergency department services in Universiti Sains Malaysia hospital. Med J Malays 59(1):26-33

3. Martin A, Martin C, Martin PB et al (2002) 'Inappropriate' attendance at an accident and emergency department by adults registered in local general practices: how is it related to their use of primary care? J Health Serv Res Policy 7(3):160-165

4. Hider P, Helliwell P, Ardagh M et al (2001) The epidemiology of emergency department attendances in Christchurch. NZ Med J 114(1129): 157-159

5. Derlet RW, Richards JR (2000) Overcrowding in the nation's emergency departments: complex causes and disturbing effects. Ann Emerg Med 35:63-68
6. Hansagi H, Olsson M, Sjöberg S et al (2001) Frequent use of the hospital emergency department is indicative of high use of other health care services. Ann Emerg Med 37:561-567

7. Sempere-Selva T, Peiró S, Sendra-Pina P et al (2001) Inappropriate use of an accident and emergency department: magnitude, associated factors, and reasons - an approach with explicit criteria. Ann Emerg Med 37:568-579

8. Pereira S, Oliveira A, Quintas M et al (2001) Appropriateness of emergency department visits in a Portuguese university hospital. Ann Emerg Med 37:580-586

9. Fernandes CMB (2003) Emergency department overcrowding: what is our response to the "new normal"? Acad Emerg Med 10 (10):1096-1097

10. Shih FY, Chen SC, Fang CC et al (1999) ED overcrowding in Taiwan: facts and strategies. Am J Emerg Med 17(2):198-202

11. Graff L (1999) Overcrowding in the ED: an international symptom of health care system failure. Am J Emerg Med 17(2):208-209

12. Hwang U, Concato $\mathrm{J}$ (2004) Care in the emergency department: how crowded is overcrowded? Acad Emerg Med 11(10):1097-101

13. Aharonson-Daniel L, Fung H, Hedley AJ (1996) Time studies in A\&E department - a useful tool for management. J Manag Med 10(3): $15-22$

14. The Harvard Team (1999) Improving Hong Kong's Health Care System: Why and For Whom? Hong Kong Special Administrative Region Government Printing Department

15. Khang YH, Lynch JW, Kaplan GA (2005) Impact of economic crisis on cause-specific mortality in South Korea. Int J Epidemiol 34(6):1291-1301

16. Kim CY (2005) The Korean economic crisis and coping strategies in the health sector: pro-welfarism or neoliberalism? Int J Health Serv 35(3):561-578

17. Hopkins S (2006) Economic stability and health status: evidence from East Asia before and after the 1990s economic crisis. Health Policy 75(3):347-357

18. Waters H, Saadah F, Pradhan M (2003) The impact of the 199798 East Asian economic crisis on health and health care in Indonesia. Health Policy Plan 18(2):172-181

19. Man CY, Yeung RSD, Chung JYM et al (2003) Impact of SARS on an emergency department in Hong Kong. J Emerg Med 15(5-6): $418-422$

20. Chen WK, Cheng YC, Chung YT et al (2005) The impact of the SARS outbreak on an urban emergency department in Taiwan. Med Care 43:168-172

21. Rainer TH, Cameron PA, Smit D, Ong KL, Hung AN, Nin DC, Ahuja AT, Si LC, Sung JJ (2003) Evaluation of WHO criteria for identifying patients with severe acute respiratory syndrome out of hospital: prospective observational study. BMJ 326:13541358

22. Population Census 2001, Census and Statistics Department, The Government of Hong Kong Special Administrative Region, 2001. http://www.censtatd.gov.hk/products_and_services/products/ individual_statistical_tables/population/index.jsp, accessed 19 May 2008

23. Cheng $\mathrm{CH}$, Graham CA, Gabbe BJ, Yeung JHH, Kossmann T, Judson RT, Rainer TH, Cameron PA (2008) Trauma care systems: a comparison of trauma care in Victoria, Australia and Hong Kong, China. Ann Surg 247:335-342

24. Cheung NK, Yeung JHH, Chan JTS, Cameron PA, Graham CA, Rainer TH (2006) Primary trauma diversion - initial experience in Hong Kong. J Trauma 61:954-960

25. Benitez MA (2002) Hong Kong tackles health-service overload by charging emergency fee. Lancet 360(9347):1757

26. New Territories Advisory Committee, Hospital Authority. Document 139: New Projects in New Territories East Cluster [Chinese]. Page 2. Hospital Authority. 6 December 2004 
27. Lau EM, Woo J, Chan JT (1997) Avoidable attendance at accident and emergency by the elderly in Hong Kong. Postgrad Med J 73(857):167-168

28. Rodriguez JL, Christmas AB, Franklin GA et al (2005) Trauma/ critical care surgeon: a specialist gasping for air. J Trauma 59(1):1-5

29. Lee A, Lau FL, Hazlett CB et al (2001) Morbidity patterns of nonurgent patients attending accident and emergency departments in Hong Kong: cross-sectional study. Hong Kong Med J 7(2):131-138

30. Lee A, Hazlett CB, Chow S et al (2003) How to minimize inappropriate utilization of Accident and Emergency Departments: improve the validity of classifying the general practice cases amongst the A\&E attendees. Health Policy 66(2):159-168
31. Law CK, Yip PS (2002) Acute care service utilisation and the possible impacts of a user-fee policy in Hong Kong. Hong Kong Med J 8(5):348-353

Colin Graham has been a Professor in the Accident and Emergency Academic Unit at the Chinese University of Hong Kong since 2007. He qualified in 1994 and undertook higher specialist training in emergency medicine in Glasgow, UK. He moved to Hong Kong in May 2004. Research interests include trauma, CPR, stroke and ED airway management. He is married with twin sons. 